\title{
NILAI TAMBAH PENGOLAHAN KACANG KEDELAI MENJADI TAHU
}

\author{
Putri Diah Pitaloka ${ }^{1}$, Supriyadi $^{2}$, Pandu Sumarna ${ }^{3}$ \\ 1,2,3 Program Studi Agribisnis, Fakultas Pertanian, Universitas Wiralodra \\ E-mail : diahpitaloka@gmail.com ${ }^{1}$, supriyadifapertaunwir@gmail.com ${ }^{2}$, sumarnapandu@gmail.com ${ }^{3}$
}

\begin{abstract}
ABSTRAK
Tujuan dari penelitian ini untuk mengetahui besar nilai tambah dan rasio nilai tambah dari pengolahan kacang kedelai menjadi tahu di Kelurahan Bojongsari Kecamatan Indramayu Kabupaten Indramayu Tahun 2018. Berdasarkan hasil penelitian menunjukkan nilai tambah yang dihasilkan dari pengolahan kacang kedelai menjadi tahu di Kelurahan Bojongsari Kecamatan Indramayu Kabupaten Indramayu Tahun 2018 adalah jika dihitung pada responden pertama untuk ukuran $6 \mathrm{~cm}$ × $6 \mathrm{~cm}$ berdasarkan output $160 \mathrm{Kg}$ per satu kali produksi yaitu Rp. 6.837,00 dengan rasio nilai tambah yang didapat jika dihitung berdasarkan output $160 \mathrm{Kg}$ yaitu 42,73\% kurang dari $50 \%$. Ukuran $8 \mathrm{~cm}$ x $8 \mathrm{~cm}$ berdasarkan output $90 \mathrm{Kg}$ per satu kali produksi yaitu Rp. 7.778,00 dengan rasio nilai tambah yang didapat jika dihitung berdasarkan output $90 \mathrm{Kg}$ yaitu 43,21\% kurang dari 50\%. Ukuran $9 \mathrm{~cm} \times 9 \mathrm{~cm}$ berdasarkan output $62,5 \mathrm{Kg}$ per satu kali produksi yaitu Rp. 7.462,00 dengan rasio nilai tambah yang didapat jika dihitung berdasarkan output $62,5 \mathrm{Kg}$ yaitu 39,80 \% kurang dari 50\%. Hasil penelitian dari responden pertama untuk tiga ukuran tergolong rendah. Responden kedua untuk ukuran $3 \mathrm{~cm}$ x $3 \mathrm{~cm}$ berdasarkan output $80 \mathrm{Kg}$ per satu kali produksi yaitu Rp. 28.197,00 dengan rasio nilai tambah yang didapat jika dihitung berdasarkan output $80 \mathrm{Kg}$ yaitu 73,43\% lebih dari 50\%. Ukuran $6 \mathrm{~cm} \mathrm{x} 6 \mathrm{~cm}$ berdasarkan output $80 \mathrm{Kg}$ per satu kali produksi yaitu Rp. 28.197,00 dengan rasio nilai tambah yang didapat jika dihitung berdasarkan output $80 \mathrm{Kg}$ yaitu 73,43\% lebih dari 50\%. Hasil penelitian dari responden kedua untuk kedua ukuran sama tergolong tinggi.
\end{abstract}

Kata Kunci : Kacang Kedelai, Nilai Tambah, , Tahu.

\section{PENDAHULUAN}

Sektor pertanian mempunyai peranan yang sangat besar dalam pertumbuhan ekonomi negara terutama negara yang bercorak agraris seperti Indonesia. Sebagai negara agraris dengan produksi hasil-hasil pertanian yang beragam, diharapkan dapat menunjang pendapatan nasional. Karena itulah diperlukan sektor industri yang ditopang oleh bidang pertanian yang tangguh.

Pembangunan pertanian diarahkan untuk meningkatkan produksi pertanian guna memenuhi kebutuhan pangan dan industri dalam negeri, meningkatkan ekspor, meningkatkan pendapatan petani, memperluas kesempatan kerja dan mendorong pemerataan kesempatan berusaha. Kacang kedelai (Glycine max, L. Merr) merupakan salah satu tanaman serelia (pangan) bernilai ekonomis tinggi yang memberikan andil cukup besar bagi pembangunan (Soekartawi, 1995).

Tedapat beberapa jenis tanaman pangan di Indonesia Khususnya di Provinsi Jawa Barat yang merupakan penyuplai hasil pertanian paling besar di Indonesia. Tentunya tanaman pangan tersebut ditanam berdasarkan kesesuaian dengan iklim, lingkungan, juga berdasarkan kebutuhan gizi dan vitamin yang dibutuhkan penduduk Provinsi Jawa Barat itu sendiri. Tanaman pangan yang ditanam dapat sesuai dengan iklim dan lingkungan pada wilayah itu sendiri maka Provinsi Jawa Barat tidak perlu menyuplai bahan pangan dari kota lain untuk memenuhi kebutuhan penduduk Provinsi Jawa Barat. 
Hasil panen kacang kedelai memang belum mencukupi kebutuhan Jawa Barat bahkan Nasional, tetapi itu cukup membuktikan bahwa Jawa Barat bisa menghasilkan kedelai yang banyak dengan kualitas yang bagus juga, tetapi kalau dilakukan terus menerus akan meningkatkan produksinya, maka paling tidak bisa mengurangi kuota impor kedelai dari luar negeri, akan tetapi di Jawa Barat terutama Indramayu masih mengandalkan kacang kedelai impor sampai sekarang.

Produksi kacang kedelai hanya terdapat di beberapa Kecamatan di Kabupaten Indramayu, diantaranya yaitu Kecamatan Haurgeulis, Kecamatan Gantar, Kecamatan Kroya, Kecamatan Gabuswetan, Kecamatan Indramayu, Kecamatan Lohbener, Kecamatan Terisi, Kecamatan anjatan, dan Kecamatan Losarang. 2012- 2016 dapat dilihat pada Tabel 1.

Tabel 1. Luas Panen, Produksi, dan Produktivitas Kacang Kedelai di Kabupaten Indramayu 20122016.

\begin{tabular}{ccccc}
\hline $\begin{array}{c}\text { No } \\
\text {. }\end{array}$ & Tahun & Luas Panen (Ha) & $\begin{array}{c}\text { Jumlah Produksi } \\
\text { Kedelai (Ton) }\end{array}$ & $\begin{array}{c}\text { Produktivitas Per } \\
\text { Hektar (Kw/Ha) }\end{array}$ \\
\hline 1 & 2012 & 791 & $1.219,64$ & 15,42 \\
2 & 2013 & 2.337 & $4.077,76$ & 17,45 \\
3 & 2014 & 22.512 & $41.988,53$ & 18,65 \\
4 & 2015 & 22.024 & $39.826,51$ & 18,09 \\
5 & 2016 & 22.142 & $40.482,08$ & 18,28 \\
\hline
\end{tabular}

Sumber : Badan Pusat Statistik Indramayu, 2018

\section{METODOLOGI PENELITIAN}

\section{Lokasi dan Waktu Penelitian}

Objek penelitian ini yaitu pemilik industri rumah tangga pengolahan Tahu, ada 5 perusahaan yang beroperasi yakni di Kelurahan Bojongsari Kecamatan Indramayu Kabupaten Indramayu. Diambil dua sampel industri rumah tangga pengolahan Tahu untuk penelitian ini karena dua perusahaan tahu ini lebih lama usahanya, ampas tahunya diolah menjadi oncom dan pakan ternak dan juga dalam pemenuhan kebutuhan kedelainya bekerjasama dengan PRIMKOPTI (Primer Koperasi Produsen Tempe Tahu Indonesia) sedangkan yang tiga lainnya tidak.

\section{Metode Pengumpulan Data}

Metode penelitian ini dilakukan dengan metode survei, yaitu metode yang dilakukan untuk mengadakan pemeriksaan dan pengukuran-pengukuran terhadap gejala empiris yang berlangsung di lapangan atau lokasi penelitian. Metode untuk mengumpulkan informasi dari kelompok yang mewakili sebuah populasi.

\section{Metode Penentuan Sampel}

Sampel ditentukan menggunakan teknik purposive sampling yaitu pengambilan sampel dengan cara sengaja, karena dua Pengusaha Tahu yang menjadi responden yang berada di Kelurahan Bojongsari berproduksi sudah cukup lama, bekerjasama dengan PRIMKOPTI dalam pemenuhan kebutuhan kedelai per bulannya, tempatnya juga strategis karena dekat dengan jalan, tempat produksinya sangat berdekatan antara dua perusahaan tahu, dan ampas tahunya diolah menjadi oncom dan pakan ternak maka usaha tersebut menarik untuk penelitian dibandingkan tiga Pengusaha Tahu lainnya (Nazir, 1988). oleh karena pertimbangan tersebut, sampel dalam penelitian ini ditentukan dua pelaku usaha di Kelurahan Bojongsari Kecamatan Indramayu Kabupaten Indramayu.

\section{Analisis Penerimaan}

Penerimaan adalah perkalian antara produksi yang dihasilkan dengan harga jual. Secara sistematis dapat ditulis sebagai berikut (Arif, 2012).

$$
\mathbf{T R}=\mathbf{Q} \times \mathbf{P}
$$

Dimana :

$\begin{array}{ll}\mathrm{TR} & \text { : Peneriman total (total revenue) } \\ \mathrm{Q} & \text { : Jumlah produk yang dihasilkan (quantity) } \\ \mathrm{P} & \text { : Harga (price) }\end{array}$ 


\section{Analisis Keuntungan}

Keuntungan merupakan hasil akhir penerimaan dikurangi dengan biaya total produksi. Secara matematis keuntungan dituliskan dengan rumus (Arif, 2012).

$\boldsymbol{\pi}=\mathbf{T R}-\mathbf{T C}$

Keterangan:

$\pi=$ Keuntungan $(\mathrm{Rp} / \mathrm{bulan})$

$\mathrm{TR}=$ Total Penerimaan $(\mathrm{Rp} / \mathrm{bulan}) \mathrm{TC}=$ Total Biaya $(\mathrm{Rp} / \mathrm{bulan})$

\section{HASIL DAN PEMBAHASAN}

\section{Proses Pembuatan Tahu}

Kedelai yang digunakan untuk membuat tahu terlebih dahulu dicuci sampai bersih setelah itu direndam ke dalam air bersih selama 8-10 jam sampai kedelai mengembang. Setelah proses perendaman selesai kedelai dicuci kembali secara berulang hingga benar-benar bersih. Proses selanjutnya adalah menghancurkan kedelai dengan cara memasukkan kedelai ke dalam mesin penggiling. Setelah kedelai tersebut menjadi bubur kemudian dimasak dan menjaga agar bubur kedelai tersebut tidak mengental. Proses pemasakan selesai maka bubur kedelai dicampurkan cuka sambil disaring dan terus diaduk secara berlahan, selanjutnya adalah menuang bubur kedelai yang telah menjadi gumpalan ke dalam cetakan dan didinginkan. Setelah proses pendinginan selesai maka tahu tersebut diiris sesuai dengan kebutuhan.

\section{Sumbangan Input Lain}

Sumbangan input lain untuk responden pertama bagian bahan penolong pada ukuran $6 \mathrm{~cm} \times 6$ $\mathrm{cm}, 8 \mathrm{~cm}$ x $8 \mathrm{~cm}$, dan $9 \mathrm{~cm}$ x $9 \mathrm{~cm}$ sebesar Rp. 6.666,67. Bahan bakar $6 \mathrm{~cm}$ x $6 \mathrm{~cm}, 8 \mathrm{~cm}$ x $8 \mathrm{~cm}$, dan $9 \mathrm{~cm}$ x $9 \mathrm{~cm}$ sebesar Rp. 147.331,333. Listrik pada ukuran $6 \mathrm{~cm}$ x $6 \mathrm{~cm}, 8 \mathrm{~cm}$ x $8 \mathrm{~cm}$, dan $9 \mathrm{~cm} \times$ $9 \mathrm{~cm}$ sebesar Rp. 1.111. Penyusutan peralatan pada ukuran $6 \mathrm{~cm} \times 6 \mathrm{~cm}, 8 \mathrm{~cm} \times 8 \mathrm{~cm}, 9 \mathrm{~cm} \times 9$ cm sebesr Rp. 4.005,48. Transportasi pada ukuran $6 \mathrm{~cm}$ x $6 \mathrm{~cm}, 8 \mathrm{~cm} \times 8 \mathrm{~cm}, 9 \mathrm{~cm} \times 9 \mathrm{~cm}$ sebesar Rp. 3.333,33. PBB pada ukuran $6 \mathrm{~cm} \times 6 \mathrm{~cm}, 8 \mathrm{~cm} \times 8 \mathrm{~cm}$, dan $9 \mathrm{~cm} \times 9 \mathrm{~cm}$ sebesar Rp. 55.555,33. Total per produksi untuk ukuran $6 \mathrm{~cm}$ x $6 \mathrm{~cm}, 8 \mathrm{~cm}$ x $8 \mathrm{~cm}$, dan $9 \mathrm{~cm}$ x $9 \mathrm{~cm}$ sebesar Rp. 218.003,14. Jumlah output per produksi untuk ukuran $6 \mathrm{~cm}$ x $6 \mathrm{~cm}$ sebanyak $160 \mathrm{~kg}, 8 \mathrm{~cm} \times 8 \mathrm{~cm}$ sebanyak $90 \mathrm{~kg}$, dan $9 \mathrm{~cm}$ x $9 \mathrm{~cm}$ sebanyak $62,5 \mathrm{~kg} /$ siklus produksi. Total per input produksi untuk ukuran $6 \mathrm{~cm} \times 6 \mathrm{~cm}$ sebesar Rp. 1.362,51, $8 \mathrm{~cm}$ x $8 \mathrm{~cm}$ sebesar Rp. 2.422,25, dan $9 \mathrm{~cm}$ x $9 \mathrm{~cm}$ sebesar Rp. 3488,05 .Sumbangan input lain untuk responden kedua dari nomor 1 sampai 9 jumlahnya sama antara kedua ukuran. Bagian bahan penolong pada ukuran $3 \mathrm{~cm} \times 3 \mathrm{~cm}$ dan $6 \mathrm{~cm} \times 6 \mathrm{~cm}$ sebesar Rp. 6.000,00, bahan bakar Rp. 126.568, listrik Rp. 6.666,5, penyusutan peralatan Rp. 1.319,86, transportasi Rp. 10.000,00, PBB Rp. 41.666,5, total per produksi sebesar Rp. 192.220,86, jumlah output per produksi sebanyak $80 \mathrm{~kg} /$ siklus produksi, dan total per input produksi sebesar Rp. 2.402,76. Adapun terkait penjelasan di atas dapat dilihat dalam tabel 2.

Tabel 2. Sumbangan Input Lain Responden Pengolahan Tahu di Kelurahan Bojongsari Kecamatan Indramayu Kabupaten Indramayu Jawa Barat Tahun 2018.

\begin{tabular}{|c|c|c|c|c|c|c|}
\hline \multirow{3}{*}{ No. } & \multirow{3}{*}{ Uraian } & \multicolumn{5}{|c|}{ Nama Responden } \\
\hline & & \multicolumn{3}{|c|}{ Musa } & \multicolumn{2}{|c|}{ Tarma } \\
\hline & & $\begin{array}{c}6 \mathrm{~cm} \mathrm{x} \\
6 \mathrm{~cm} \\
\end{array}$ & $\begin{array}{c}8 \mathrm{~cm} \mathrm{x} \\
8 \mathrm{~cm}\end{array}$ & $\begin{array}{c}9 \mathrm{~cm} \mathrm{x} \\
9 \mathrm{~cm} \\
\end{array}$ & $\begin{array}{r}3 \mathrm{~cm} \mathrm{x} \\
3 \mathrm{~cm} \\
\end{array}$ & $\begin{array}{c}6 \mathrm{~cm} \mathrm{x} \\
6 \mathrm{~cm} \\
\end{array}$ \\
\hline 1. & $\begin{array}{l}\text { Bahan Penolong } \\
\text { (Rp) }\end{array}$ & $6.666,67$ & $6.666,67$ & $6.666,67$ & $6.000,00$ & $6.000,00$ \\
\hline 2. & $\begin{array}{l}\text { Bahan Bakar } \\
\text { (Rp) }\end{array}$ & $147.331,33$ & $147.331,33$ & $147.331,33$ & $126.568,00$ & $126.568,00$ \\
\hline 3. & Listrik (Rp) & 1.111 & 1.111 & 1.111 & $6.666,5$ & $6.666,5$ \\
\hline
\end{tabular}




\begin{tabular}{|c|c|c|c|c|c|c|}
\hline 4. & $\begin{array}{l}\text { Penyusustan } \\
\text { Peralatan (Rp) }\end{array}$ & 4.005 .48 & 4.005 .48 & 4.005 .48 & $1.319,865$ & $1.319,865$ \\
\hline 5. & Transportasi & $3.333,33$ & $3.333,33$ & $3.333,33$ & $10.000,00$ & $10.000,00$ \\
\hline 6. & PBB & $55.555,33$ & $55.555,33$ & $55.555,33$ & $41.666,5$ & $41.666,5$ \\
\hline 7. & $\begin{array}{l}\text { Total Per } \\
\text { Produksi (Kg) }\end{array}$ & 218.003,14 & 218.003,14 & 218.003,14 & $192.220,86$ & $192.220,86$ \\
\hline 8. & $\begin{array}{l}\text { Jumlah Output } \\
\text { Per Produksi }\end{array}$ & 160 & 90 & 62,5 & 80 & 80 \\
\hline 9. & $\begin{array}{l}\text { Total Per Input } \\
\text { Produksi (Rp) }\end{array}$ & $1.362,51$ & $2.422,25$ & $3.488,05$ & $2.402,76$ & $2.402,76$ \\
\hline
\end{tabular}

\section{Bahan Bakar}

Berdasarkan Tabel 13 dapat dilihat Bapak Musa menggunakan 35,71 $\mathrm{Kg}$ kayu bakar dan 40 liter solar per siklus produksi, dan Bapak Tarma menggunakan 35,71 Kg kayu bakar dan 20 liter solar per siklus produksi. Penggunaan bahan bakar dalam proses pengolahan tahu sangat mempengaruhi terhadap proses produksi sehingga perlu dihitung beban biaya yang dikeluarkan. Biaya bahan bakar yang dikeluarkan Bapak Musa sebesar Rp. 441.994,00 dan biaya bahan bakar yang dikeluarkan Bapak Tarma sebesar Rp. 253.136,00.

\section{Listrik}

Berdasarkan Tabel 14 menunjukkan bahwa Bapak Musa membayar listrik Rp. 100.000,00/Bulan dengan harian kerja 7 hari dan membayar sebesar Rp. 3.333/Siklus produksi, dan Bapak Tarma Rp. 400.000,00/Bulan dengan harian kerja 7 hari dan membayar Rp. 13.333/Siklus produksi.

Tabel 3. Biaya Bahan Bakar Kayu dan Solar dari Kedua Responden Pengolah Tahu di Kelurahan Bojongsari Kecamatan Indramayu Kabupaten Indramayu Jawa Barat Tahun 2018.

\begin{tabular}{ccccccccc}
\hline No. & Nama & $\begin{array}{c}\text { Kayu } \\
\text { Bakar } \\
(\mathrm{Kg} / \mathrm{Hari})\end{array}$ & $\begin{array}{c}\text { Solar } \\
(\mathrm{Liter})\end{array}$ & $\begin{array}{c}\text { Harga } \\
\text { Kayu } \\
\text { Bakar } \\
(\mathrm{Rp} / \mathrm{Kg})\end{array}$ & $\begin{array}{c}\text { Harga } \\
\text { Solar Per } \\
(\text { Liter })\end{array}$ & $\begin{array}{c}\text { Karga } \\
\text { Kayu } \\
\text { Bakar } \\
(\mathrm{Rp})\end{array}$ & $\begin{array}{c}\text { Harga } \\
\text { Solar } \\
(\text { Liter })\end{array}$ & $\begin{array}{c}\text { Biaya } \\
\text { Bahan } \\
\text { Bakar } \\
(\mathrm{Rp})\end{array}$ \\
\hline 1. & Musa & 35,71 & 40 & $1.600,00$ & $9.800,00$ & $49.994,00$ & $392.000,00$ & $441.994,00$ \\
2. & Tarma & 35,71 & 20 & $1.400,00$ & $9.800,00$ & $57.136,00$ & $196.000,00$ & $253.136,00$ \\
\hline
\end{tabular}

Sumber : Lampiran 4.

Tabel 4. Penggunaan Tenaga Listrik dari Kedua Responden Pengolah Tahu Per Siklus Produksi di Kelurahan Bojongsari Kecamatan Indramayu Kabupaten Indramayu Jawa Barat Tahun 2018.

\begin{tabular}{|c|c|c|c|}
\hline No. & Nama & Biaya listrik/Bulan (Rp) & $\begin{array}{l}\text { Biaya Listrik Per Siklus } \\
\text { Produksi (Rp) }\end{array}$ \\
\hline 1. & Musa & $100.000,00$ & 3.333 \\
\hline 2. & Tarma & $400.000,00$ & 13.333 \\
\hline
\end{tabular}

Sumber : Lampiran 3 


\section{Nilai Tambah Pengolahan Tahu}

Nilai tambah merupakan selisih antara nilai produk olahan dengan biaya. Analisis nilai tambah dihitung untuk mengetahui pertambahan kedelai menjadi tahu, untuk menghitung nilai tambah tahu tersebut digunakan analisis nilai tambah dengan pendekatan struktur produksi.

Dapat dilihat pada tabel 18 dan 19 nilai tambah diperoleh dari selisih antara nilai produk dengan harga bahan baku serta sumbangan input lain. Nilai tambah dari kedua responden yaitu, responden pertama dengan ukuran $6 \mathrm{~cm}$ x $6 \mathrm{~cm}$ diperoleh nilai tambah sebesar Rp. 6,837,00 dengan ratio nilai tambah sebesar $42,73 \%$, ukuran $8 \mathrm{~cm} \times 8 \mathrm{~cm}$ diperoleh nilai tambah sebesar Rp. 7.778,00 dengan ratio nilai tambah 43,21\%, ukuran $9 \mathrm{~cm}$ x $9 \mathrm{~cm}$ diperoleh nilai tambah sebesar Rp. 7.462,00 dengan ratio nilai tambah 39,80\%. Responden kedua dengan ukuran $3 \mathrm{~cm}$ x $3 \mathrm{~cm}$ diperoleh nilai tambah sebesar Rp. 28.197,00 dengan ratio nilai tambah 73,43\% dan ukuran $6 \mathrm{~cm}$ x $6 \mathrm{~cm}$ diperoleh nilai tambah sebesar Rp. 28.197,00 dengan ratio nilai tambah 73,43\%. Nilai tambah tersebut merupakan nilai tambah kotor karena masih mengandung pendapatan tenaga kerja dan bagian tenaga kerja.

Tabel 5. Hasil Analisis Nilai Tambah Pengolahan Kacang Kedelai menjadi Tahu Per Siklus Produksi Bapak Musa di Kelurahan Bojongsari Kecamatan Indramayu Kabupaten Indramayu Jawa Barat Tahun 2018.

\begin{tabular}{|c|c|c|c|c|c|}
\hline \multirow{3}{*}{ No. } & \multirow{3}{*}{ Variabel } & \multirow{3}{*}{ Notasi } & \multicolumn{3}{|c|}{ Nilai Per Kg } \\
\hline & & & $6 \mathrm{~cm} \mathrm{x}$ & $8 \mathrm{~cm} \mathrm{x}$ & $9 \mathrm{~cm} \mathrm{x}$ \\
\hline & & & $6 \mathrm{~cm}$ & $8 \mathrm{~cm}$ & $9 \mathrm{~cm}$ \\
\hline 1. & Output (kg/proses produksi) & A & 160 & 90 & 62,5 \\
\hline 2. & Input (kg/proses produksi) & $\mathrm{B}$ & 100 & 60 & 40 \\
\hline 3. & Tenaga kerja (HOK/proses produksi) & $\mathrm{C}$ & 1 & 1 & 1 \\
\hline 4. & Faktor konversi & $\mathrm{D}=\mathrm{A} / \mathrm{B}$ & 1,6 & 1,5 & 1,6 \\
\hline 5. & $\begin{array}{l}\text { Koefisien tenaga kerja } \\
(\mathrm{HOK} / \mathrm{kg})\end{array}$ & $\mathrm{E}=\mathrm{C} / \mathrm{B}$ & 0,01 & 0,02 & 0,03 \\
\hline 6. & Harga output (Rp/kg) & $\mathrm{F}$ & 10.000 & 12.000 & 12.000 \\
\hline 7. & $\begin{array}{l}\text { Upah rata-rata tenaga kerja } \\
(\mathrm{Rp} / \mathrm{HOK})\end{array}$ & $\mathrm{G}$ & 50.000 & 50.000 & 50.000 \\
\hline 8. & Harga bahan baku (Rp/kg) & $\mathrm{H}$ & 7.800 & 7.800 & 7.800 \\
\hline 9. & Sumbangan input lain $(\mathrm{Rp} / \mathrm{kg})$ & $\mathrm{I}$ & $1.362,52$ & $2.422,26$ & $3.488,05$ \\
\hline \multicolumn{6}{|c|}{ Penerimaan dan Keuntungan } \\
\hline 10. & Nilai output/produk $(\mathrm{Rp} / \mathrm{kg})$ & $\mathrm{J}=\mathrm{d} \times \mathrm{f}$ & 16000 & 18000 & 18750 \\
\hline 11. & a. Nilai tambah (Rp) & $\mathrm{K}=\mathrm{j}-\mathrm{h}-\mathrm{i}$ & 6.837 & 7.778 & 7.462 \\
\hline \multirow{3}{*}{12.} & b. Ratio nilai tambah (\%) & $\mathrm{L} \%=(\mathrm{k} / \mathrm{j}) \times 100 \%$ & 42,73 & 43,21 & 39,80 \\
\hline & a. Imbalan tenaga kerja $(\mathrm{Rp} / \mathrm{kg})$ & $M=e \times g$ & 500 & 833,3 & 1250 \\
\hline & b. Bagian tenaga kerja (\%) & $\mathrm{N} \%=(\mathrm{m} / \mathrm{k}) \times 100 \%$ & 7,31 & 10,71 & 16,75 \\
\hline \multirow[t]{2}{*}{13.} & a. Keuntungan $(\mathrm{Rp} / \mathrm{kg})$ & $\mathrm{O}=\mathrm{k}-\mathrm{m}$ & 6.337 & 6.944 & 6.212 \\
\hline & b. Tingkat keuntungan (\%) & $\mathrm{P} \%=(\mathrm{o} / \mathrm{k}) \times 100 \%$ & 92,69 & 89,29 & 83,25 \\
\hline \multirow[t]{4}{*}{14.} & Marjin (Rp) & $\mathrm{Q}=\mathrm{j}-\mathrm{h}$ & 8.200 & 10.200 & 10.950 \\
\hline & a. Pendapatan tenga kerja (\%) & $\mathrm{R} \%=(\mathrm{m} / \mathrm{q}) \times 100 \%$ & 6,10 & 8,17 & 11,42 \\
\hline & b. Sumbangan input lain & $\mathrm{S} \%=(\mathrm{i} / \mathrm{q}) \times 100 \%$ & 16,62 & 23,75 & 31,85 \\
\hline & c. Keuntungan perusahaan (\%) & $\mathrm{T} \%=(\mathrm{o} / \mathrm{q}) \times 100 \%$ & 77,29 & 68,08 & 56,73 \\
\hline
\end{tabular}


Tabel 6. Hasil Analisis Nilai Tambah Pengolahan Kacang Kedelai menjadi Tahu Per Siklus Produksi Bapak Tarma di Kelurahan Bojongsari Kecamatan Indramayu Kabupaten Indramayu Jawa Barat Tahun 2018.

\begin{tabular}{|c|c|c|c|c|}
\hline \multirow{2}{*}{ No. } & \multirow{2}{*}{ Variabel } & \multirow{2}{*}{ Notasi } & \multicolumn{2}{|c|}{ Nilai Per Kg } \\
\hline & & & $3 \mathrm{~cm} \times 3 \mathrm{~cm}$ & $6 \mathrm{~cm} \times 6 \mathrm{~cm}$ \\
\hline 1. & Output (kg/proses produksi) & A & 80 & 80 \\
\hline 2. & Input (kg/proses produksi) & $\mathrm{B}$ & 50 & 50 \\
\hline 3. & $\begin{array}{l}\text { Tenaga kerja (HOK/proses } \\
\text { produksi) }\end{array}$ & $\mathrm{C}$ & 2 & 2 \\
\hline 4. & Faktor konversi & $\mathrm{D}=\mathrm{A} / \mathrm{B}$ & 3,2 & 3,2 \\
\hline 5. & $\begin{array}{l}\text { Koefisien tenaga kerja } \\
(\mathrm{HOK} / \mathrm{kg})\end{array}$ & $\mathrm{E}=\mathrm{C} / \mathrm{B}$ & 0,08 & 0,08 \\
\hline 6. & Harga output $(\mathrm{Rp} / \mathrm{kg})$ & $\mathrm{F}$ & 12.000 & 12.000 \\
\hline 7. & $\begin{array}{l}\text { Upah rata-rata tenaga kerja } \\
\text { (Rp/HOK) }\end{array}$ & G & 50.000 & 50.000 \\
\hline 8. & Harga bahan baku (Rp/kg) & $\mathrm{H}$ & 7.800 & 7.800 \\
\hline 9. & Sumbangan input lain $(\mathrm{Rp} / \mathrm{kg})$ & I & $2.402,76$ & $2.402,76$ \\
\hline \multicolumn{5}{|c|}{ Penerimaan dan Keuntungan } \\
\hline 10. & Nilai output/produk $(\mathrm{Rp} / \mathrm{kg})$ & $\mathrm{J}=\mathrm{dxf}$ & 38400 & 38400 \\
\hline 11. & a. Nilai tambah (Rp) & $\mathrm{K}=\mathrm{j}-\mathrm{h}-\mathrm{i}$ & 28.197 & 28.197 \\
\hline & b. Ratio nilai tambah (\%) & $\mathrm{L} \%=(\mathrm{k} / \mathrm{j}) \times 100 \%$ & 73,43 & 73,43 \\
\hline 12. & a. Imbalan tenaga kerja $(\mathrm{Rp} / \mathrm{kg})$ & $M=e \times g$ & 4000 & 4000 \\
\hline & b. Bagian tenaga kerja (\%) & $\mathrm{N} \%=(\mathrm{m} / \mathrm{k}) \times 100 \%$ & 14,19 & 14,19 \\
\hline 13. & a. Keuntungan $(\mathrm{Rp} / \mathrm{kg})$ & $\mathrm{O}=\mathrm{k}-\mathrm{m}$ & 24.197 & 24.197 \\
\hline & b. Tingkat keuntungan (\%) & $\mathrm{P} \%=(\mathrm{o} / \mathrm{k}) \times 100 \%$ & 85,81 & 85,81 \\
\hline 14. & Marjin (Rp) & $\mathrm{Q}=\mathrm{j}-\mathrm{h}$ & 30.600 & 30.600 \\
\hline & a. Pendapatan tenga kerja (\%) & $\mathrm{R} \%=(\mathrm{m} / \mathrm{q}) \times 100 \%$ & 13,07 & 13,07 \\
\hline & b. Sumbangan input lain & $\mathrm{S} \%=(\mathrm{i} / \mathrm{q}) \times 100 \%$ & 7,85 & 7,85 \\
\hline & c. Keuntungan perusahaan (\%) & $\mathrm{T} \%=(\mathrm{o} / \mathrm{q}) \times 100 \%$ & 79,08 & 79,08 \\
\hline
\end{tabular}

\section{SIMPULAN DAN SARAN}

Hasil analisis yang telah dilakukan pada usaha olahan tahu di Kelurahan Bojongsari Kecamatan Indramayu Kabupaten Indramayu maka dapat diambil beberapa simpulan yaitu :

1. Besarnya nilai tambah yang dihasilkan dari pengolahan kedelai menjadi tahu di Kelurahan Bojongsari Kecamatan Indramayu Kabupaten Indramayu pada responden pertama dengan ukuran $6 \mathrm{~cm}$ x $6 \mathrm{~cm}$ sebesar Rp. 6.837,00, ukuran $8 \mathrm{~cm}$ x $8 \mathrm{~cm}$ sebesar Rp7.778,00, dan ukuran $9 \mathrm{~cm}$ x 9 cm sebesar Rp. 7.462,00. Responden kedua dengan ukuran $3 \mathrm{~cm}$ x 3 cm sebesar Rp. 28.197,00 dan ukuran $6 \mathrm{~cm}$ x $6 \mathrm{~cm}$ sebesar Rp. 28.197,00.

2. Rasio nilai tambah yang dihasilkan dari pengolahan kedelai menjadi tahu di Kelurahan Bojongsari Kecamatan Indramayu Kabupaten Indramayu untuk responden pertama dengan ukuran $6 \mathrm{~cm}$ x $6 \mathrm{~cm}$ sebesar 42,73\%, ukuran $8 \mathrm{~cm}$ x $8 \mathrm{~cm}$ sebesar 43,21\%, dan ukuran $9 \mathrm{~cm}$ x 9 $\mathrm{cm}$ sebesar $39,80 \%$. Dari respoden pertama ratio nilai tambah yg paling tinggi ada pada ukuran 8 $\mathrm{cm}$ x $8 \mathrm{~cm}$ sebesar 43,21\%<50\% maka nilai tambah tergolong rendah. Responden kedua 
dengan ukuran $3 \mathrm{~cm}$ x $3 \mathrm{~cm}$ sebesar 73,43\% dan ukuran $6 \mathrm{~cm}$ x $6 \mathrm{~cm}$ sebesar 73,43\%. Dari responden kedua ratio nilai tambah yang paling tinggi ada pada ukuran keduanya $3 \mathrm{~cm} \times 3 \mathrm{~cm}$ dan $6 \mathrm{~cm} \times 6 \mathrm{~cm}$ sebesar 73,43\%>50\% maka nilai tambah tergolong tinggi.

\section{Saran}

Saran yang dapat diberikan hasil penelitian yang telah dilakukan pada usaha pengolahan kedelai menjadi tahu di Kelurahan Bojongsari Kecamatan Indramayu Kabupaten Indramayu adalah :

1. Adanya nilai tambah yang dihasilkan dari suatu produk tahu diharapkan pengusaha tahu dapat mengembangkan produk tahu dengan menggunakan kemasan agar tahu yang dijual lebih menarik terlebih lagi jika pada kemasan di beri label agar lebih dikenal masyarakat luas.

2. Bagi pemerintah Kelurahan Bojongsari Kecamatan Indramayu Kabupaten Indramayu harus memberikan dukungan dalam upaya meningkatkan pemasaran produk tahu lebih luas lagi.

\section{Ucapan Terimakasih}

Ucapan Terimaksih saya ucapkan kepada Fakultas Pertanian dan LPPM UNWIR yang telah membantu dalam penelitian ini sehingga penelitian dapat dijalankan.

\section{DAFTAR PUSTAKA}

Andika, Rio. 2015. Analisis Nilai Tambah Kedelai pada Produk Industri Rumah tangga Pengolahan Tahu di Kecamatan Natar Kabupaten Lampung Selatan. Fakultas Pertanian. Sekolah Tinggi Ilmu Pertanian Dharma Wacana Metro. Lampung.

Azis, Yusuf., 2012. Adaptasi Ekonomi Pengusaha Agribisnis Tahu dalam Menghadapi Keaikan Harga Kedelai di Kabupaten Banjar. Fakultas Pertanian. Universitas Lambung Mangkurat. Banjarbaru.

Badan Pusat Satistik. 2017. Kabupaten Indramayu Dalam Angka 2016. Badan Pusat statistik. Indramayu.

Badan Pusat Statistik. 2019. Kecamatan Indramayu dalam Angka 2018. Badan Pusat Statistik. Indramayu.

Budiman, Arif. 2012. Analisis Efisiensi dan Nilai Tambah Agoindustri Tahu di Kota Pekanbaru. Jurnal Fakultas Pertanian. Universitas Riau. Pekanbaru.

Cahyono. 2007. Teknik Budidaya dan Analisis Usaha Tani Kedelai. CV

Aneka Ilmu. Semarang.

Kurniati. 2008. Kedelai. Indobook Citra Media. Bogor

Nazir, M. 1988. Metode Penelitian. Cetakan ketiga. Ghalia Indonesi:Jakarta

Nurmedika. 2013. Analisis Pendapatan dan Nilai Tambah Keripik Nangka pada

Industri Rumah Tangga Tiara di Kota Palu. Jurnal Fakultas Pertanian. Sumber http://www.jsea.viewfile.wordpress.com[15/5/2018]

Payne, Adrian. 1995. Pemasaran Jasa; The Essence of Service Marketing. Andi. Yogyakarta.

Primer Koperasi Produsen Tempe dan Tahu (PRIMKOPTI). 2018. Kebutuhan Kedelai per Bula pada Beberapa Kecamatan di Kabupaten Indramayu. Primer Koperasi Produsen Tempe dan Tahu (PRIMKOPTI). Indramayu. 
Pemerintah Kelurahan Bojongsari. 2018. Profil Kelurahan Bojongsari Tahun 2018. Indramayu.

Pusat Data dan Sistem Informasi Pertanian. 2015. Outlook Komoditas Pertanian Tanaman Pangan Kedelai. Pusat Data dan Sistem Informasi Pertanian. Kementrian Pertanian.

Ramadhanti. 2017. Pengaruh Bauran Pemasaran (7P) Terhadap Keputusan Pembelian pada Giant Supermarket Mall Mesra Indah di Samarinda. Jurnal Fakultas Ilmu Pemerintahan. Universitas Mulawarman.

Ruminih. 2015. Analisis Nilai Tambah Emping Melinjo (Gnetum gnemon, L). Usulan Penelitian. Fakultas Pertanian. Universitas Wiralodra. (Tidak di Publikasikan).

Santoso. 2005. Teknologi Pengolahan Kedelai (Teori Praktik). Universitas Widyagama. Malang.

Sarwono, B dan Saragih. 2001. Membuat Aneka Tahu. Penebar Swadaya. Jakarta

Sukirno. 2009. Mikroekonomi Teori Pengantar. Rajawali Pers. Jakarta

Soekartawi. 1995. Analisis Usahatani. UI press. Jakarta.

Sofwan. 2013. Analisis Kelayakan Usaha Pemasaran Tahu Pong di Kabupaten Indramayu. Usulan Penelitian. Fakultas Pertanian. Universitas Wiralodra Indramayu.Tidak di Publikasikan.

Sorga., dkk. 2013. Analisis Komparasi Nilai Tambah dalam Berbagai Produk Olahan Kedelai pada Industri Rumah Tangga di Kota Medan. Jurnal Fakultas Pertanian. Universitas Sumatra Utara.

Suratiyah, Ken. 2009. Ilmu Usahatani. Edisi ketiga, PT. Penebar Swadaya : Jakarta. 